\title{
Water, Water Everywhere: Meeting the Demands of Saudi Arabia's Water Needs *
}

\author{
Aradhya Sood, Namgyal Angmo, and Yukiko Iwasaki
}

October 21, 2014

\begin{abstract}
The objective of this paper is to introduce models to determine an effective, feasible, and cost-efficient strategy for Saudi Arabia's water supply system to meet its projected demand in 2025. This paper uses cost minimizing and production maximizing approaches to build the models. The water management system is divided into three processes-desalination, distribution, and wastewater treatment. For desalination and wastewater treatment aspects of the water supply, we use a Cobb-Douglas production maximization model. The model determines the optimal levels of different inputs that maximize the production of usable water, given the Saudi Arabia government's budget constraints. For the water distribution model, a cost function is minimized with the 2025 water demand constraint and is used to determine the optimal diameter of the pipes and hydraulic head. Using the desalination process model, the paper found that the optimal level of input of electricity is 4.9 billion $k W h$ and the maximized water output is estimated at 3.3 billion $\mathrm{m}^{3}$. In addition, using the wastewater treatment model, the paper found that the optimal level of electricity input is 26.5 billion $k W h$ annually and the maximized level of water production is 7.7 billion $\mathrm{m}^{3}$. The water distribution model estimates that, given the 2025 water demand in Saudi Arabia, the set-up and operating cost of the water distribution grid is approximately $\$ 68.88$ million. The model also estimates that a minimum pipe diameter of $5.37 \mathrm{~m}$ and hydraulic head of $1186.14 \mathrm{~m}$ is required to meet the demand of three sectors-agriculture, industry, and domestic.
\end{abstract}

\section{Introduction}

The Kingdom of Saudi Arabia is an excellent example of a nation that has overcome its harsh geographical setting and environmental scarcity of water and made astonishing progress over the last several decades to address the situation of water scarcity. Massive investments by the Saudi government in projects such as environmentally sustainable agriculture and desalination technologies have helped the nation develop. However, as the standard of living improves and infrastructure expands, the consumption of water is multiplying more

\footnotetext{
*This paper was an Outstanding Winning paper in COMAP's Mathematical Contest in Modeling 2013.
} 
than ever before. In light of rapidly increasing water demand, there are rising concerns over whether the government will be able to sustain its current approach to water supply. Although the government is introducing measures and policy decisions to move towards more efficient allocations of water resources, illustrated by steps taken to cut wheat subsidy in the 1990s and the plan to phase out domestic wheat production entirely by 2016 (Water and National Strength in Saudi Arabia, March 2016), there is a need to assess and remodel existing processes of water supply to improve their economic and production efficiency.

Any strategic planning for water supply systems must consider the issues illustrated above while designing appropriate mechanisms for the nation. Here we present our water management model which strives to cover all the critical aspects of the water supply scheme, with a special focus on ensuring that the current supply and consumption is sustainable and meets the 2025 projected water demand. We highlight three cost efficient and sustainable models for different aspects of Saudi Arabia's water supply. Firstly, we maximize water production using Reverse Osmosis as a desalination process for seawater; secondly, we minimize the cost of water distribution using an efficient distribution mechanism; and thirdly, we maximize wastewater recycling that adds to the water production in Saudi Arabia. For the models of desalination and wastewater treatment, a Cobb-Douglas production maximization model is used to determine the optimal levels of inputs of electricity and other factors of production to maximize the total production of water.

\section{Models for Water Management in Saudi Arabia}

Figure 1 illustrates a simplified system to manage the water demands of Saudi Arabia. Saudi Arabia has sea water on both eastern and western coast of the country (see Figure 2 ). Since most of the water supply of Saudi Arabia comes from desalinated water, this process is the primary water supplier. Desalinated water goes for consumption through a water distribution system. After the used water is treated, it is either discharged or used for consumption again. Figure 1, thus, provides a layout for the three models that are explained below. These include a model for the desalination process, the water distribution process, and the water treatment process.

\section{The Models}

\subsection{A model for maximizing de-salted water production in desali- nation plants}

\subsubsection{Desalination - background}

In today's scenario of depleting sources and increasing demand, desalination provides alternative fresh water sources by making saline water from oceanic or underground sources usable for irrigation, municipal or industrial purposes. This is crucial since out of the vast majority of the earth's water which is located in the lakes and oceans, only about one percent is considered usable freshwater for human consumption. It provides a key strategy 


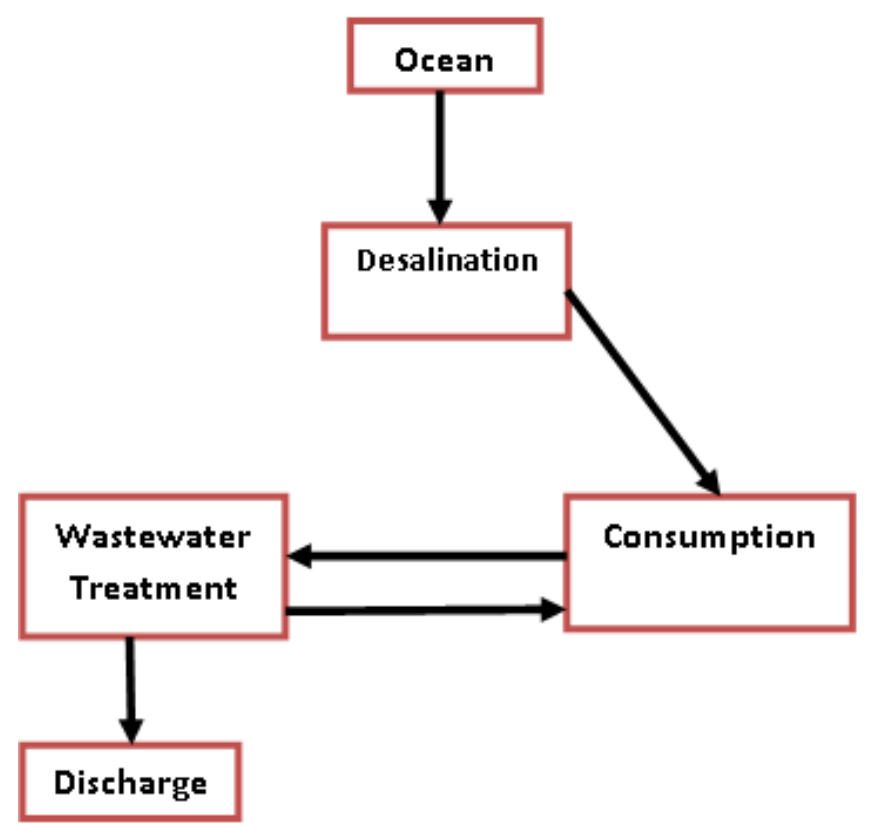

Water Management Process in Saudi Arabia

Figure 1: Water Management Process in Saudi Arabia

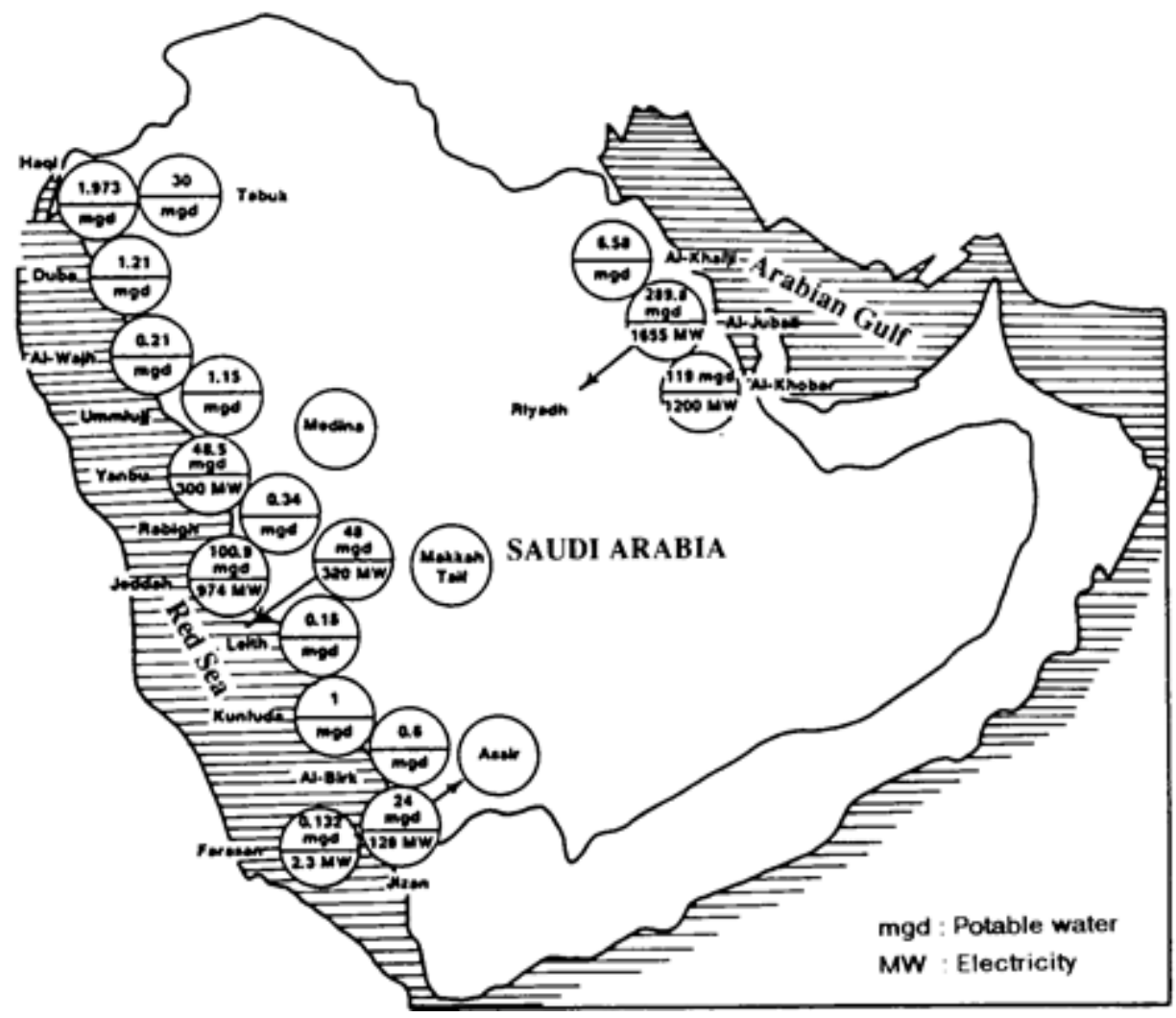

Figure 2: Desalination Plants in Saudi Arabia (Murakami, 1995) 
to tap into the vast available sources to meet water demands especially in coastal areas and areas with large brackish or underground water sources. Desalination consists of methods to reduce the amount of dissolved salt and other impurities such as biological or organic chemical compounds in saline water by using various separation processes such as thermal and membrane based desalination. Thermal desalination methods have been used for a longer time and involve evaporation and condensation to separate salt from water while membrane based methods use techniques where water diffuses through a membrane. The most widely used thermal and membrane based desalination processes are Multi-stage flash distillation (MSF) and Reverse Osmosis (RO) respectively (Figure 3). Although desalination has huge potential benefits for regions with water scarcity, the economic costs, energy consumption and the lack of regional and resource compatibility along with environmental impacts remain major deterrents in the way of its wide commercialization.

\subsubsection{Saudi Arabia - the largest producer of desalinated water}

Currently, the Persian Gulf islands, with limited local supplies, and some selected other areas in the region, where water options are limited and the public is willing to pay high prices, have the most significant seawater desalination capacities. The Middle East is the largest desalination market in the world with Saudi Arabia leading the worldwide production of desalinated water. Seventy percent of Saudi Arabia's drinking water demand is met by seawater desalination performed by over thirty operating plants which distribute the desalinated water to major urban and industrial areas through an extensive water distribution system (Rodriguez, 2011-12). In 2010, more than 1,103 million cubic meters of desalinated water was produced. MSF and RO are the most commercially important and extensively used desalination processes with the future trend leaning more towards RO because of its lower cost and simplicity.

Reverse Osmosis is a pressure driven process where the impure saline feed water is pressurized against a membrane that rejects dissolved constituents to produce drinking water. The amount of desalinated water that can be produced ranges between $30 \%$ to $85 \%$ of the volume of the input water depending on the initial water quality, the quality of the product needed, and the technology and membrane involved. The development of improved membranes and energy recovery systems has and are continuing to reduce the cost of the RO process and have made it the most significant and viable desalination process.

\subsubsection{Previous work in modelling Desalinated Water Production}

Given the importance of desalination as a water resource for Saudi Arabia, a desert country with a rapidly growing economy and increasing resource demands, the continuous development of high productivity resource collection and distribution models is vital for ensuring sustained development. Zagouras et al (1989) have carried out statistical and econometric analysis of the costs and operations of a desalination plant and identified the underlying economic production function to be of the Cobb-Douglas form given below. 


$$
W=F^{0.6} H^{0.4}
$$

where $W$ represents cubic meters of desalted water produced, $F$ represents factors of production (an aggregation of evaporating pumps, maintenance of those pumps, and labor) and $H$ represents the level of heat used for the evaporation process.

Zagouras et al (1989) classify inputs of water desalination into two groups: those for which the cost per unit of desalted water is increasing and those for which this cost is decreasing. This permits them to express production of desalted water as a function of two aggregates of inputs. Data from the Zagouras et al (1989) model was obtained and evaluated under the condition that the plant operates under maximum loads continuously throughout the year except for maintenance periods. This analysis in terms of complementarity and substitution among the different factors of production and inputs led to the formulation of the above Cobb-Douglas production function given above. It also provided the relative emphasis given to the two inputs: $60 \%$ to $F$ and $40 \%$ to $H$.

The analysis in terms of the average desalination costs and different production levels led to the formulation of a long term average cost function as well. This is given below.

$$
B=P_{F} F+P_{H} H
$$

where $P_{F}$ represents the price per unit of the aggregate factors of production, $P_{H}$ represents the price per unit of level of heat used (in terms of price of electricity) and $B$ represents the allocated budget for the Reverse Osmosis sector.

Hence the production of desalinated water can be optimized by maximizing the production function under the budget constraint i.e. the total cost for inputs should not exceed the allocated government budget for desalination.

\subsubsection{Model Assumptions}

We will assume that the Cobb-Douglas model can be extended specifically to apply to Reverse Osmosis plant production, similar to how it was applied to the more traditional Thermal Desalination Plant in the above study. The model constructed assumes that the entire budget allocation will be directed towards one desalination facility which represents the aggregate production of all the plants that make up the desalination industry in Saudi Arabia. It will then be optimized to arrive at a maximum level of water output per year, represented by the output variable $W$ (in terms of cubic meters of desalted water produced per year) under the budget constraint in (2).

The following assumptions are made in terms of the variable inputs and constraints in the model:

- The desalination plants have constant returns to scale. 
- The variable $F$ is an aggregate input variable that represents the level of all the factors of production that go into the process of desalination.

- The input for the level of heat $H$ is considered to be equivalent to the input for electrical energy, and hence will be interpreted as the required amount of electrical energy that needs to be supplied for optimum production. (in $k W h$ )

- The price per unit variables $P_{F}$ and $P_{H}$ are taken to be the most recent aggregate cost per cubic meter of production $\left(\$ 0.46\right.$ per $\left.\mathrm{m}^{3}\right)$ and cost of electricity required per cubic meter of desalinated water production $\left(\$ 0.21\right.$ per $\left.\mathrm{m}^{3}\right)$ respectively. The cost of electricity was found using the price of electricity per $k W h$ in Saudi Arabia $(\$ 0.03$ per $k W h)$ and estimates for the average electrical consumption per cubic meter production of desalinated water $\left(7 \mathrm{kWh}\right.$ per $\left.\mathrm{m}^{3}\right)$.

- The constraint provided by the budget $B$, is assumed to be a percentage of Saudi Arabia's 2013 national budget towards water related projects. We assume forty percent to be directed towards desalination projects, thus giving us a budget of $\$ 2.56$ billion.

\subsubsection{Final Optimization Model}

With the above assumptions, we have the final optimization problem:

Maximize

$$
W=F^{0.6} H^{0.4}
$$

Subject to

$$
0.46 F+0.21 H \leqslant 2.56 \times 10^{9}
$$

where

- $W=$ Cubic meters of desalted water produced per year using Reverse Osmosis

- $F=$ A measure of the level of input factors of production per year (an aggregation of plant equipment, maintenance, and labor)

- $H=$ Amount of electrical energy used (in $k W h$ ) in the reverse osmosis process per year.

\subsubsection{Optimization Results}

Using Mathematica to optimize the above problem, we obtain following optimum levels of output, the input factors of production and heat input levels:

- Maximum volume of water production per year $W=3.9 \times 10^{9} \mathrm{~m}^{3}$ per year

- Level of input aggregate factors of production $F=3.3 \times 10^{9}$ units per year

- Level of heat/electrical energy input $H=4.9 \times 10^{9} \mathrm{kWh}$ per year 


\subsubsection{Sensitivity Analysis}

The robustness of the model can be examined by analyzing the sensitivity of the model's output to changes in input. We will test our model using several variable inputs and observing the resulting outputs and the level of variations. This is summarized in the table below.

\begin{tabular}{|c|c|c|c|}
\hline \% Budget & Max Output (billion $m^{3}$ ) & F (billions) & $\mathbf{H ~}(k W h)$ \\
\hline 34 & 3.30 & 2.84 & 4.14 \\
\hline 36 & 3.50 & 3.01 & 4.34 \\
\hline 38 & 3.69 & 3.17 & 4.63 \\
\hline $\mathbf{4 0}$ & $\mathbf{3 . 8 6}$ & $\mathbf{3 . 3 4}$ & $\mathbf{4 . 8 8}$ \\
\hline 42 & 4.08 & 3.51 & 5.12 \\
\hline 44 & 4.27 & 3.67 & 5.36 \\
\hline Price/F (\$) & Max Output (billion $m^{3}$ ) & F (billions) & $\mathbf{H ~}(k W h)$ \\
\hline 0.40 & 4.22 & 3.84 & 4.88 \\
\hline 0.42 & 4.10 & 3.66 & 4.88 \\
\hline 0.44 & 3.99 & 3.49 & 4.88 \\
\hline $\mathbf{0 . 4 6}$ & $\mathbf{3 . 8 6}$ & $\mathbf{3 . 3 4}$ & $\mathbf{4 . 8 8}$ \\
\hline 0.48 & 3.79 & 3.20 & 4.88 \\
\hline 0.5 & 3.70 & 3.07 & 4.88 \\
\hline Price/H (\$) & Max Output (billion $m^{3}$ ) & $\mathbf{F ~ ( b i l l i o n s ) ~}$ & $\mathbf{H}(k W h)$ \\
\hline 0.15 & 4.44 & 3.34 & 6.83 \\
\hline 0.17 & 4.23 & 3.34 & 6.02 \\
\hline 0.19 & 4.04 & 3.34 & 5.39 \\
\hline $\mathbf{0 . 2 1}$ & $\mathbf{3 . 8 6}$ & $\mathbf{3 . 3 4}$ & $\mathbf{4 . 8 8}$ \\
\hline 0.23 & 3.79 & 3.34 & 4.45 \\
\hline 0.25 & 3.62 & 3.34 & 4.10 \\
\hline
\end{tabular}

Table 1: Sensitivity Analysis for Desalination Production Model (Main results are bold)

We can observe from the above table that changes in the constraints and inputs lead to changes in output as expected - higher budget causes output to increase while increases in the prices per unit of the input factors causes the output to decrease. If we examine the effect of variable changes on the input factors, we see that an increase in the budget is associated with higher levels of input factors as expected. However, although increases in prices per unit of production factors is associated with a lower input level of the factor whose price was increased, the input level of the other factor remains constant throughout. This is contrary to our expectation that higher prices per unit of one factor of production would have some impact on the use of other production factors. This could possibly point to some weaknesses in the estimation of the portion of the cost of water production that arises due to electrical energy costs and the portion that comes from other production factors. The price per unit used for the aggregate factors of production $F$ might already account for energy costs. Another possibility is that the model tries to keep the input for the other production factors constant and only adjusts the input for the factor whose price changed, which could in practice ensure that the overall quality of production does not change significantly. 


\subsubsection{Strengths and Limitations of the Model}

One of the strengths of the model is the wide applicability and simplicity of the CobbDouglas production function for the Desalination which allows us to easily examine optimal input allocations for maximized output. Another important feature of the model is that it separates input factors of production into an aggregate input factor and an energy factor. This is useful given that energy input forms one of the most important aspects of the water resource area in Saudi Arabia. This model can thus allow for a distinctive analysis of the level of investment that needs to be directed into energy sources.

Although the model does provide a valuable tool for optimizing the desalination process, the above maximization process has a number of limitations due to the lack of availability of exact figures for prices per unit of inputs and government budget allocations to desalination projects. In this light, several assumptions were made which might make our results quite unrealistic in terms of practical application to the water management scenario in Saudi Arabia keeping the 2025 projected demands in mind. Better data would make the model more extendable to applications in the desalination industry situation in Saudi Arabia.

\subsection{A model for Minimizing Distribution Costs of Water}

\subsubsection{Water Distribution-A Background}

Once the water is stored in a reservoir from different supply streams, the water is distributed to agricultural sector, industries, and households. There are two ways by which water is usually distributed. In the branched method, each node, representing a water consumption body, has only one pipeline or link connected to it. In this system there is one main pipeline and smaller pipelines connect the main pipe to the individual nodes (Figure 4). Another method for water distribution is a looped method where more than one pipeline is connected to each node. In this system, thus, every node can receive water from at least two sources (Figure 4).

\subsubsection{Model Assumptions}

- The model illustrates the water distribution system for both branched and looped system.

- There are two factors, diameter of piping and hydraulic head, that affect the cost of distribution of water.

- The topography of Saudi Arabia is flat like a 2-D surface and does not include any contours, mountains, and valleys.

- There is no resistance or friction of water in the pipes or at the nodes.

- The distance between nodes or the length of the linking pipes is given, along with the level of consumption at each node. 


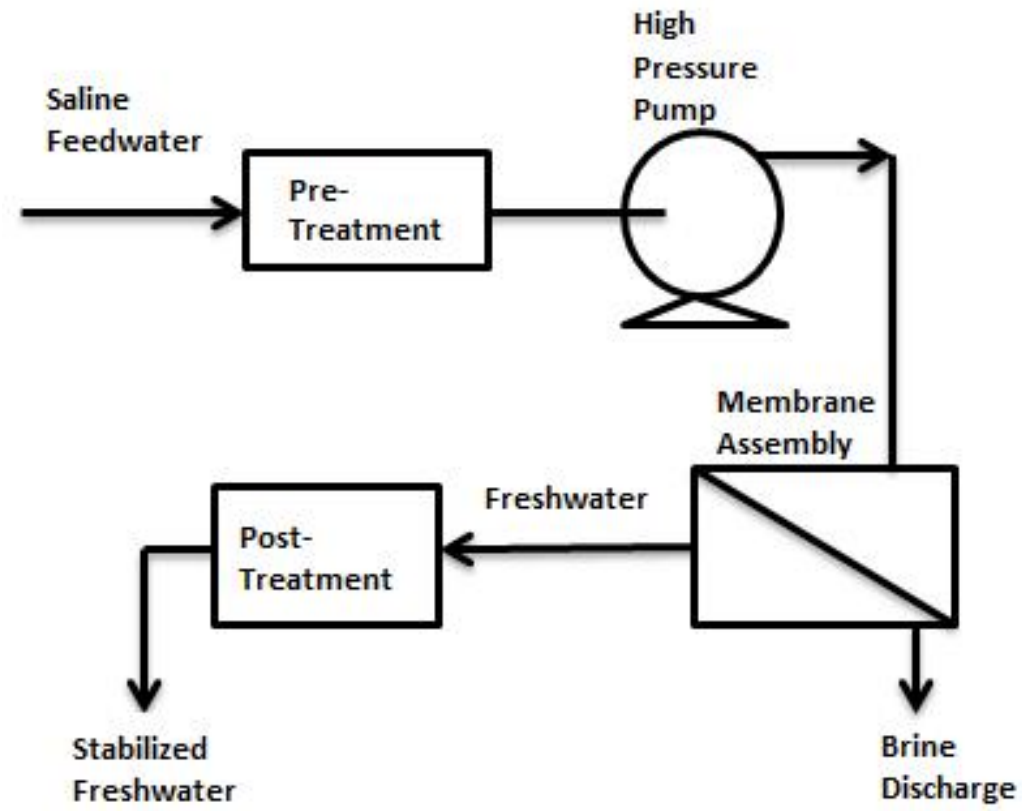

Figure 3: Flow Diagram of Reverse Osmosis System (Khan, 1986)

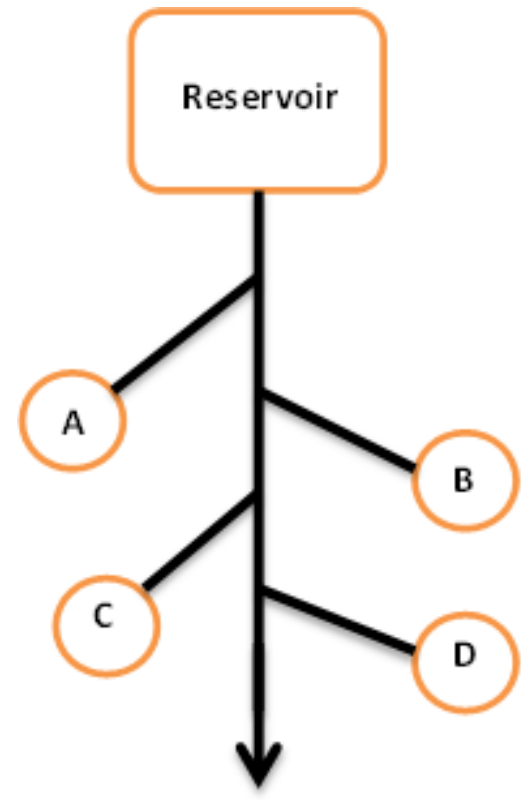

Branched System

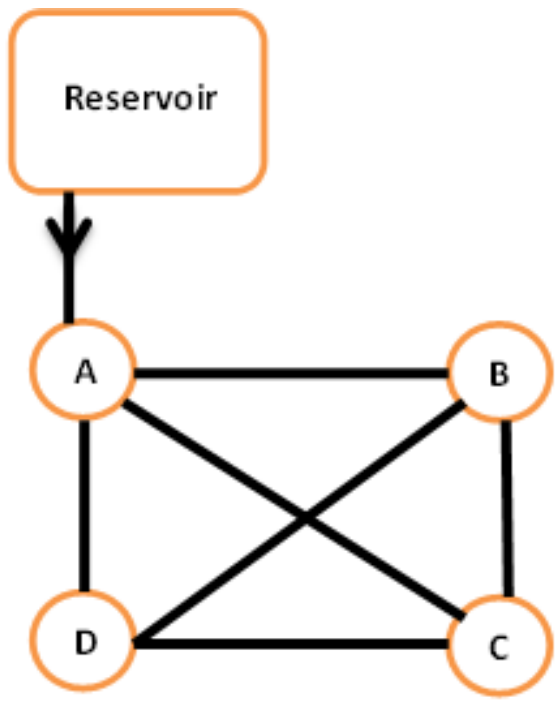

Looped System

Figure 4: Water Distribution Methods 
- The model does not have a valve system to stop the water flow in the pipes i.e. once the water is released from the reservoir, it will continue to flow through the pipe in the grid of nodes and links.

- The model assumes that the consumption of water at each node is known.

\subsubsection{The Model}

The model seeks to minimize total cost, including the fixed or capital costs and variable or operational costs, in the water distribution system. The total cost function is minimized given the constraint that the total demand of water in Saudi Arabia is met. Thus, the model seeks to optimize the cost of supply of water while meeting the demands of the three main sectors-agriculture, households, and industries.

The fixed cost in the model is a function of the length $L$, the distance between each node of consumption, and the diameter $d$ of the piping network (Shamir, 1974). The length of the pipes is given in the model because usually the distances between existing industries and households cannot be changed. The diameter of the pipes, on the other hand, is a variable calculated by solving the optimization problem. Both length and diameter of the pipe are directly proportional to the capital cost in the water distribution system as more material and labor costs are required when the piping system is longer and bigger. The fixed cost sum is introduced below where $i$ is the number of pipes among different nodes, $\alpha$ is a fixed cost constant, and $\beta$ is the economies of scale factor for diameter in fixed cost.

$$
\alpha \sum_{i=1}^{N} L_{i} d^{\beta}
$$

The variable cost is a function of the amount of consumption $c$ of water at each node, the diameter $d$ of the piping, and the hydraulic head $h$ (a measure of liquid pressure) of the water flowing through the pipes (Shamir, 1974). The variable cost sum is given below where $\gamma$ is variable cost constant, $o$ is the loading level, $j$ is the number of nodes, thet $a$ is economies of scale factor for the diameter, and $p h i$ is the economies of scale factor for the hydraulic head.

$$
\gamma \sum_{o=1}^{O} \sum_{j=1}^{J}\left(c_{j}\right)^{o} d^{o \theta} h^{o \phi}
$$

The diameter of piping is directly proportional to the operating cost because the greater the diameter of the pipe, larger the maintenance costs, especially when the pipes break or there are leakages. Additionally, the greater is the diameter of a pipe, the larger is the volumetric flow rate i.e. greater are the costs as more energy is required for a larger flow rate. Volumetric flow rate is the volume of water that passes through a given surface per unit time. Hydraulic head is also directly related to the operating cost. Greater the liquid pressure with which water flows in the pipes, greater pumping energy is required, resulting in higher costs. In addition, the variable cost also depends on the level of loading $o$ that 
occurs at any given point of time during a period of time (Shamir, 1974). Level of Loading is the changing demand for the consumption of water during a day or year. Loading $o$ takes into account that water consumption may be higher during mornings or the tourist season of the year. Given the changing level of consumption of water in a given period of time, the operational cost also varies. Thus, a distribution system may have a higher loading i.e. higher consumption during $30 \%$ of a day and lower loading for the rest of the day.

When the capital and operational costs are added, a total cost function is created. The function includes a fixed cost constant $\alpha$ and a variable cost constant $\gamma$ which are determined using the data available. The total cost function is given by the following.

Total Cost $(\mathrm{d}, \mathrm{h})=$ Fixed Cost + Variable Cost

$$
\operatorname{TotalCost}(d, h)=\alpha \sum_{i=1}^{N} L_{i} d^{\beta}+\gamma \sum_{o=1}^{O} \sum_{j=1}^{J}\left(c_{j}\right)^{o} d^{o \theta} h^{o \phi}
$$

The constraint is calculated using the following equation, where flow rate $Q$ is given by the

ratio of total demand of water and unit time, $g$ is the gravitational constant, and $h$ is the hydraulic head.

$$
\begin{gathered}
Q=\text { Area } * \text { Velocity } \\
Q=\frac{\pi d^{2}}{4} * \sqrt{2 g h} \\
Q=3.5 d^{2} \sqrt{h}
\end{gathered}
$$

\subsubsection{Parameter Estimation}

The parameters listed above are estimated using empirical studies on water distribution systems in United States. Even though costs and factors of economies of scale are probably different in United States and Saudi Arabia, the empirical work on Saudi Arabia's water distribution system was lacking. Given that (Heaney et al, 1999) estimate the pipe construction cost per foot to be $\$ 15$ for an inch of diameter in the 1998 dollar terms, in 2012 terms the pipe construction cost per meter for a meter of pipe diameter is calculated to be $\$ 827$. Thus, $\alpha$, the fixed cost constant, is estimated as 827 . Heaney et al estimate the flow rate constant as 218. When calculated in conjunction with 2012 and the flow rate equation, $\gamma$, the variable cost constant is 763 . According to this study, $\beta, \theta$, and $\phi$ have values less than 1 . This means that economies of scale is being achieved both in fixed and variable costs i.e. water distribution system has cost advantages due to the large size. Thus, $\beta$ is estimated as $0.6, \theta$ is estimated as 0.8 , and $\phi$ is estimated as 0.4385 (Heaney et al, 1999). 


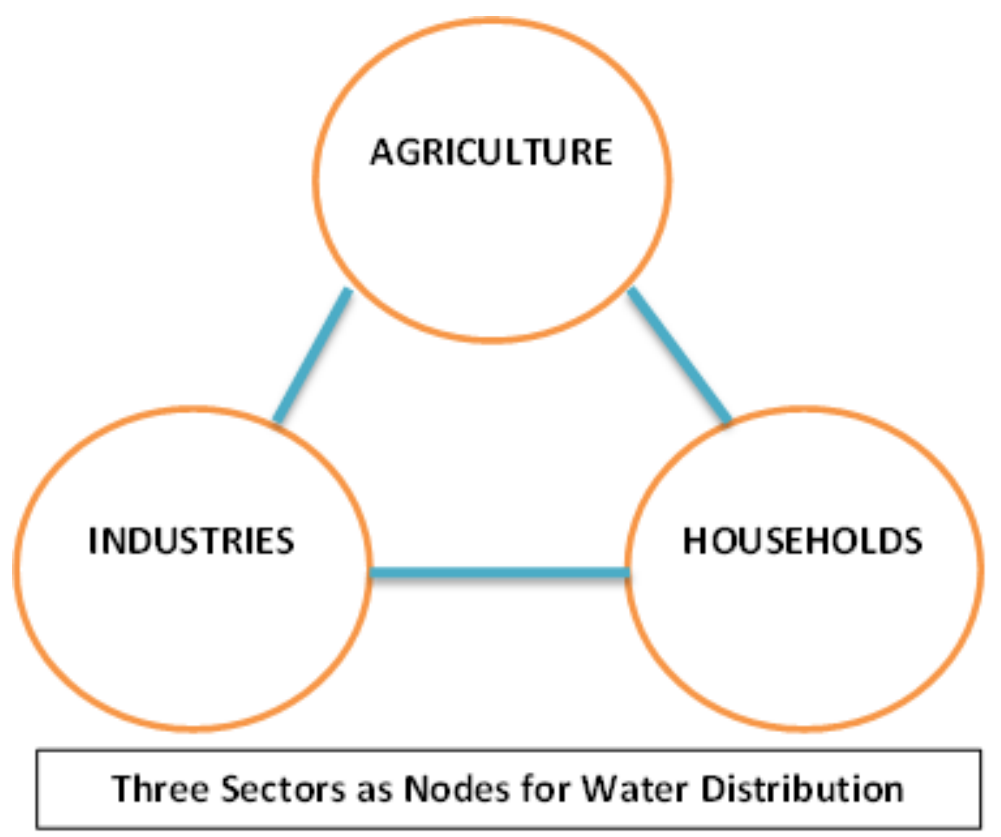

Figure 5: Three Water Consumption Sectors as Nodes for Water Distribution

\subsubsection{The Results}

When the model is run using the software Mathematica, we get the following results. For this simulation, the total Saudi Arabia's water demand for 2025 is divided by into the three main sectors-agriculture, industries, and households, given that agriculture accounts for $88 \%$ water use in Saudi Arabia with 3\% usage by industries and $9 \%$ usage by households (Abderrahman, 2006). Thus, there are three nodes representing agriculture, industry, and household with consumption $c_{j}$ of $876.41 \frac{\mathrm{m}^{3}}{\mathrm{~s}}, 29.81 \frac{\mathrm{m}^{3}}{\mathrm{~s}}$, and $89.74 \frac{\mathrm{m}^{3}}{\mathrm{~s}}$, respectively. In this hypothetical example, the links or pipes are assumed to be of the length $L_{i} 490 \mathrm{~m}, 485 \mathrm{~m}$, and $500 \mathrm{~m}$, respectively and $o=3$. The three sectors are assumed to be about a half kilometer away from each other $\left(L_{i}\right)$ to provide a layout of consumption nodes that are neither too close to each other like a household neighborhood nor too far like an industrial area.

After optimizing, the results indicate that the total cost for laying out and operating a water distribution system, given the hypothetical distances between the nodes and the consumption by each of the main three sectors, is $\$ 68.88$ million. This result also generates a minimized pipe diameter of $5.37 \mathrm{~m}$ and hydraulic head of $1186.14 \mathrm{~m}$. Thus, if there were only three nodes of consumption that are laid out at the distance mentioned above, then to meet the demand, $\$ 68.88$ million will have to be spent on the water distribution system. In the simulation laid out in this section, it was assumed that there is only one level of loading, i.e. three nodes have a constant demand of water.

\subsubsection{Sensitivity Analysis}

The robustness of the model explained above is measured in this section. If the lengths of pipelines and the amount of water consumed is altered, we get the results as illustrated in 
the table below. The table illustrates that greater the length of pipeline or larger the level of consumption, greater is the cost for laying and operating the distribution system.

\begin{tabular}{|c|c|c|c|c|}
\hline Total Length & Total Consumption & Cost in $\$$ & $d$ in $m$ & $h$ in $m$ \\
\hline $\mathbf{1 4 7 5 m}$ & $\mathbf{9 9 6} \frac{m^{3}}{s}$ & $\mathbf{6 8 . 8 8} \mathbf{~ m i l}$ & $\mathbf{5 . 3 7}$ & $\mathbf{1 1 8 6 . 1 4}$ \\
\hline $98 \mathrm{~m}$ & $3.8 \frac{\mathrm{m}^{3}}{\mathrm{~s}}$ & 61,650 & 0.28 & 17.23 \\
\hline $2450 \mathrm{~m}$ & $27.41 \frac{\mathrm{m}^{3}}{\mathrm{~s}}$ & 221,743 & 0.32 & 114 \\
\hline
\end{tabular}

Table 2: Cost, Diameter, and Hydraulic Head for a Given Length and Consumption (Main results are in bold)

Additionally, the greater the projected demand/consumption of water, the bigger the minimized diameter of the pipes and the minimized hydraulic head is. Thus, the model does not seem to be very sensitive to large and small input values of pipeline length and water consumption.

\subsubsection{Strengths and Weaknesses of the Model}

Even though the model presented above only takes into account the pipe diameter and hydraulic head as two inputs among many other inputs of a cost function, it generates robust results that align with empirical research. Additionally, this model also takes into account the differences in consumption that may occur at each node in the distribution grid. Furthermore, the model acknowledges that the distances between nodes (whether it be a residential or industrial area) is usually a given factor and cannot be changed. The level of loading adds another dimension to the model by taking into account the differing amounts of water consumption at any given period of time.

Nevertheless, the model does have some limitations. Firstly, since the number of pipes and nodes need to be modeled discretely, the level of loading is also being modelled discretely. This may not reflect the actuality of water distribution as the changes in level of loading happen continuously. Secondly, the cost model does not take into account the water loss that may occur from leakages and pipe breaks, a common problem in Saudi Arabia. Thirdly, the model assumes that the 2-D like distribution grid, discounting the affect gravity will have on the pressure (hydraulic head) of water.

\subsection{A Model for Maximizing the Production in Wastewater Treat- ment Plants}

An important aspect of water management in Saudi Arabia is to reuse wastewater, especially if energy consumption by desalination plants is to be reduced (Kajenthira et al, 2012). The model given below is a Cobb-Douglas production function model, similar to the desalination process. 


\subsubsection{Assumptions}

- Constant returns to scale $a+b=1$

- Unfortunately there was no data found on the input of electricity and factors of production and outputs. If the data were present, the method of least square regression would be used to estimate both $a$ and $b$. We assume $a$ and $b$ to be 0.4 and 0.6 respectively.

- Both inputs of electricity and other factors of production are proportional to the output.

- Cost of electricity and other factors of productions are determined by the price of electricity times the quantity of electricity needed per $\mathrm{m}^{3}$ and cost of other factors of production per $m^{3}$.

- $p^{f}=\$ 0.038$ per $m^{3}$ (Seckler et al, 1998)

- $P^{e}=\$ 0.46$ per $m^{3}$ (Seckler et al, 1998)

$\$ 6.4$ billion dollars (SR 24 billion) will be spent on water resources by building dams and desalination plants, using deep aquifers wells, expanding and improving water and water treatment networks (U.S-Saudi Arabian Business Council). Since there was no information found on the breakdown of this budget, the budget for the wastewater treatment would be assumed to be $30 \%$ of the total budget. Thus, $\mathrm{B}=\$ 2.56$ billion.

\subsubsection{Model}

$$
W=F^{a} E^{b}
$$

Maximize the function where the constraint is

$$
C=F \cdot P^{f}+E \cdot P^{e} \leq B
$$

- $\mathrm{W}=$ Total water production

- $\mathrm{F}=$ Factors of Production

- $\mathrm{E}=$ Electricity

- $P^{e}=$ Cost of electricity per $m^{3}$ water

- $P^{f}=$ Cost of factor of production per $m^{3}$ water

- $\mathrm{C}=$ Total cost of water production

- $\mathrm{B}=$ Government Budget 


\subsubsection{Results}

The function was maximized with the constraint. The optimized values for the quantities of electricity and other factors of production are estimated

$$
\begin{aligned}
& \mathrm{F}=3.339 \times 10^{9} \text { units } \\
& \mathrm{E}=2.65 \times 10^{10} \mathrm{kWh} \\
& \mathrm{W}=7.65 \times 10^{9} \mathrm{~m}^{3}
\end{aligned}
$$

\subsubsection{Sensitivity Analysis}

As the budget increases, the total production increases, however with diminishing returns. When the fraction of the budget is increased from $10 \%$ to $20 \%$, there is a $100 \%$ increase in the maximum output while when the budget is increased from $90 \%$ to $100 \%$, the increase in the maximum output is only $10 \%$. This is explained by the fact that as the the budget is increased by $0.1, F, E$, and $W$ each increase by the same absolute amount of $0.83,6.64$, and 1.91, respectively. In addition, the optimal electricity input grows a lot faster than other factors of production.

\begin{tabular}{|c|c|c|c|}
\hline \% Budget & $\mathbf{F}$ (units) & $\mathbf{E}(k W h)$ & $\mathbf{W}\left(m^{3}\right)$ \\
\hline 0.1 & 0.83 & 6.64 & 1.91 \\
\hline $\mathbf{0 . 2}$ & $\mathbf{1 . 6 6}$ & $\mathbf{1 3 . 2 8}$ & $\mathbf{3 . 8 2}$ \\
\hline 0.3 & 2.50 & 19.90 & 5.74 \\
\hline 0.4 & 3.33 & 26.56 & 7.65 \\
\hline 0.5 & 4.17 & 33.20 & 9.56 \\
\hline 0.6 & 5.00 & 39.8 & 11.48 \\
\hline 0.7 & 5.89 & 46.48 & 13.30 \\
\hline 0.8 & 6.67 & 53.10 & 15.30 \\
\hline $\mathbf{0 . 9}$ & $\mathbf{7 . 5 1}$ & $\mathbf{5 9 . 7 0}$ & $\mathbf{1 7 . 2 2}$ \\
\hline 1 & 8.34 & 66.40 & 19.10 \\
\hline
\end{tabular}

Table 3: Optimal Level of Input for Electricity and Other Factors of production with Varying Budget (Main Results are in Bold)

\subsubsection{Strengths and Weaknesses of the Model}

Since there was no information found on the breakdown of inputs for the wastewater treatment plants, the constants $a$ and $b$ could not be determined. This may have caused inaccuracy in the result. In addition, if there were more information available on the prices and quantities of labor, materials and other different factors of productions, the production function could have been a product of more variables. This may give us the optimal level of labor, chemicals and other factors of production. Furthermore, when calculating the price of factors of productions per $\mathrm{m}^{3}$ production of water, it was uncertain whether the data obtained included electricity cost. If it did include the cost, it may explain partially why the change in government budget caused much greater increase in optimal input level for electricity than in other factors of production. 
Despite these drawbacks of the model, it can be practically applied with enough information on the inputs and the outputs. In addition, the model can be integrated with the desalination model to estimate the optimal fraction of the budget to be spent on desalination and wastewater treatment.

\section{Conclusion}

The final result of the desalination shows that $4.9 \times 10^{9} \mathrm{kWh}$ of energy should be used to maximize the output. The maximized output with the budget we have assumed is 3.9 $\mathrm{km}^{3}$ of water annually. This is more than the total projected demand in 2025 which is 3.14 $\mathrm{km}^{3}$ (Kajenthira et al, 2012). However, considering the fact that $88 \%$ of the projected water demand for 2025 is designated for agricultural sector, if the agricultural activity could be reduced by two-thirds, the water production will be able to meet the demand for domestic and industrial use, with less energy resources spent on desalination process. The estimated optimal input of electricity and other factors of production for wastewater treatment plants are $2.265 \times 10^{10} \mathrm{kWh}$ and $3.33 \times 10^{9}$ units and the maximized output is $7.65 \times 10^{9} \mathrm{~m}^{3}$ which is far more than the 2025 projected wastewater of $1.75 \times 10^{6} \mathrm{~m}^{3}$ (Kajenthira et al, 2012). This shows that if $40 \%$ of the budget is spent on the wastewater treatment, Saudi Arabia can easily reach $100 \%$ sewage rate in 2025 . Finally, the distribution model estimated the optimal values for the diameter of pipelines to be $5.37 \mathrm{~m}$ and the hydraulic head to be $1187.14 \mathrm{~m}$. The minimized cost of production is estimated to be $\$ 68.8$ million.

\section{References}

[1] Kajenthira, Arani, Afreen Siddiqi, and Laura Diaz Anadon. "A new case for promoting wastewater reuse in Saudi Arabia: Bringing energy into the water equation." Journal of environmental management 102 (2012): 184-192.

[2] Seckler, David, U. Amarasinghe, D. Molden, R. de Silva, and R. Barker. World water demand and supply, 1990 to 2025: Scenarios and Issues. Colombo, Sri Lanka: International Water Management Institute (IIMI); IWMI. vi, 40p. IIMI Research Report 19/IWMI Research Report 19). doi: 10.3910, 2009.

[3] Zagouras, N. G., Y. G. Caouris, and E. T. Kantos. "Production and cost functions of water low-temperature solar desalination." Applied Economics 21, no. 9 (1989): 11771189.

[4] Rodriguez, L. L. (2011-12). Desalination: Towards a sustainable source of drinking water. EnviroNews, (20), 6-7. Retrieved from http://www.saudiaramco.com/content/dam/Publications/Environews/Environews

Winter 2011/Desalination.pdf

[5] Desalination.(2012-12-21). Retrieved on February 1, 2013 from http://www.water.ca.gov/desalination/ 
[6] Shamir, Uri. "Optimal design and operation of water distribution systems." Water Resources Research 10, no. 1 (1974): 27-36.

[7] Heaney, James P., David Sample, and Len Wright. "Cost analysis and financing of urban water infrastructure." Innovative urban wet-weather flow management systems (1999): $10-1$.

[8] Abderrahman, Walid A. "Water management in ArRiyadh." Water Resources Development 22, no. 2 (2006): 277-289.

[9] Khan, Arshad Hassan. Desalination processes and multistage flash distillation practice. Amsterdam: Elsevier, 1986.

[10] Murakami, Masahiro. Managing water for peace in the middle east; alternative strategies. United Nations University Press, 1995. 